\title{
COMPARISON OF HMDSO AND HMDSZ THIN FILMS GROWTH UNDER DUSTY PLASMA CONDITIONS
}

\author{
'Roman PŘIBYL, 'Štěpánka KELAROVÁ, 'Lukáš ZÁBRANSKÝ, 'Vilma BURŠíKOVÁ \\ ${ }^{1}$ Faculty of Science, Department of Physical Electronics, R\&D Center for Plasma and Nanotechnology \\ Surface Modifications, CEPLANT, Brno, Czech Republic,EU, romanpribyl@mail.muni.cz
}

https://doi.org/10.37904/nanocon.2020.3778

\begin{abstract}
The present study is focused on the preparation of thin films by plasma enhanced chemical vapor deposition (PEDCV) in capacitively coupled plasma (CCP). Thin films were deposited from a mixture of oxygen and hexamethyldisiloxane (HMDSO) or hexamethyldisilazane (HMDSZ). Both monomers are well known and enable to prepare films with excellent properties such as high hardness, good abrasion resistance, hydrophobicity, and antibacterial properties. Also, these monomers are known for the creation of complex structures in plasma. This phenomenon is so-called dusty plasma. The main aim of the present work was to prepare a comparative study on the dust formation in both monomers. Complex study of surface and mechanical properties and chemical composition was done by a wide range of analytical instruments such as atomic force microscopy (AFM), nanoindentation technique, confocal microscopy, infrared spectroscopy with Fourier transformation (FTIR), stylus profilometer, and surface energy evaluation system (SEE system).
\end{abstract}

Keywords: Thin films, PECVD, dusty plasma, surface properties

\section{INTRODUCTION}

The organosilicons andorganosilazanes are widely studied precursors for plasma depositions. They are studied due to the chemical bond between silicon and carbon, this bond is weaker than the bond between two carbons in the organic chain [1]. This weaker bond can be used for the deposition of $\mathrm{SiO}_{x}$ and $\mathrm{SiN}_{x}$ materials, which are crucial insulators in the semiconductor industry. HMDSO and HMDSZ are frequently used for their suitable properties for plasma depositions and high vapor pressure [2,3]. The chemical structure of both precursors is displayed in Figure 1.

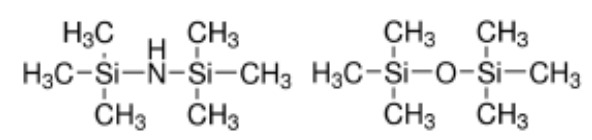

Figure 1 Structural formulas of HMDSZ and HMDSO

Properties of deposited thin films are controlled by process conditions (bias voltage, pressure, power input, etc.), but mainly are guided by the combination of precursor and carrier gas $[4,5]$. There are a large number of studies that are focused on the study of these two precursors, but they are all made in different reactors. It is a well-known fact, that the geometry of the reactor influences the self-bias voltage on the capacitively coupled electrode and that self-bias is one of the most important process parameter of PECVD. Due to this verity, we made the study of the deposition of thin films using the combination of oxygen (carrier gas) and HMDSO or HMDSZ (precursors) in the same reactor [6].

The combination of oxygen and HMDSO was previously studied due to formation of dust in plasma during the deposition process [7]. Dusty plasma was firstly observed in the universe, where the formation of dust was 
caused by part of comets [8]. In the laboratory environment was dusty plasma observed during plasma processes for microelectronic devices in silane $\left(\mathrm{SiH}_{4}\right)$ and hydrogen-carbon plasmas $\left(\mathrm{C}_{2} \mathrm{H}_{2}\right.$, etc.) [8-10]. After that, there were several studies which were mainly focused on the dusty plasma of organosilicones containing methyl groups $\left(\mathrm{CH}_{3}\right)$ which can in plasma react similarly to hydrogen-carbon plasmas and after binding layout of methyl groups there may occur similar reactions like in silane plasmas. The formation of dust is a complex problem because the formation of dust contributes to heterogeneous and homogenous reactions in plasma. The formation of dust can be an unwanted process during microelectronic processes. Contrariwise dusty plasma has a high growth rate and by dusty plasma can be grown micro and nanocomposite thin film, which has high hydrophobicity and report viscoelastic properties.

In this study, we prepared thin films using mixtures of oxygen and HMDSO or HMDSO. We studied the chemical composition, surface, and mechanical properties of deposited thin films. For the formation of dusty plasma three different values of power supply were used. The main focus was on analysis of thin films surface with AFM because the surface appearance can lead to the quantification of the formation of dusty particles and their size.

\section{EXPERIMENTAL}

Thin films were deposited in previously developed plasma reactor [6]. All thin films were deposited from a mixture of $5.0 \mathrm{sccm}$ oxygen and $2.0 \mathrm{sccm}$ precursor under deposition pressure around $15 \mathrm{~Pa}$. The deposition times were carried out between $30 \mathrm{~s}$ to $600 \mathrm{~s}$ to achieve a different thicknesses of thin films. The power input was held on $25 \mathrm{~W}, 50 \mathrm{~W}$, and $75 \mathrm{~W}$ to determine the different formation of dust. During all deposition were collected data (bias, reflected power, etc.) through the digital output of the generator. Thin films were deposited on silicon (Boron doped, (100), 0.008-0.013 $\Omega \cdot \mathrm{cm}, 625 \pm 15 \mu \mathrm{m}$ ) double-polished silicon (Phosphorus doped, (100), 0.1954-0.2034 $\Omega \cdot \mathrm{cm}, 381 \pm 25 \mu \mathrm{m}$ ) and glass. For determination of chemical composition a doublepolished silicon wafer was used. Glass substrates were used for the determination of water contact angle and for other analyzes only one side-polished silicon wafers were used.

The thickness of thin films was measured by stylus profilometer Bruker DektakXT with stylus radius of $2.5 \mu \mathrm{m}$. The thickness was measured from the interface thin film - substrate, which was obtained by the removal of a small part of the thin film on the silicon substrate. The growth rate was calculated from thickness and deposition time.

For the measurement of surface properties three different devices were used. First one - the confocal microscope was used for imaging of the film surface after deposition. Confocal microscope Olympus OSL4100 was used to display the presence of dust immediately after deposition. For determination of water contact angle (WCA) SEE system was used WCA of water drops with volume of $1.0 \mu \mathrm{m}$ placed on films deposited on glass substrates were measured after removal of physisorbed dust. The measurement of surface roughness was conducted on AFM - Ntegra Prima NT-MDT in semi-contact mode. The roughness of the samples was calculated from scans with a resolution of $512 \times 512 \mathrm{dpi}$ and scanning rate from $0.5 \mathrm{~Hz}$ to $0.7 \mathrm{~Hz}$ (the scanning rate was chosen with respect to dust particles sizes).

Chemical composition of thin films was measured by FTIR. The measurement was conducted in wavenumber range from $3700 \mathrm{~cm}^{-1}$ to $7500 \mathrm{~cm}^{-1}$ with 500 scans and resolution of $8 \mathrm{~cm}^{-1}$. The measurements were performed using Bruker vertex $80 \mathrm{v}$ device.

Mechanical properties of thin films were determined by Hysitron TI950 Triboindenter. We used a load function with 20 a partial unloading segments in order to determine the mechanical properties in different indentation depths. The maximum load was $1.000 \mathrm{mN}$. To illustrate the viscoelastic behaviour of thin films, we also used quasi-static load function with a maximal load of $1.000 \mathrm{mN}$. 


\section{RESULTS AND DISCUSSION}

From literature $[4,5]$ it is well known, that in processes with longer deposition times grow thicker films (unless there is an etching process involved), also it is known, that deposition rate decreases during the deposition process. A decrease in the deposition process during the deposition of non-conductive thin films can be caused by the evolution of self- bias voltage on the substrate holder electrode. Self-bias voltage evolution during the deposition with HMDSZ precursor with different power input is shown in Figure 2.

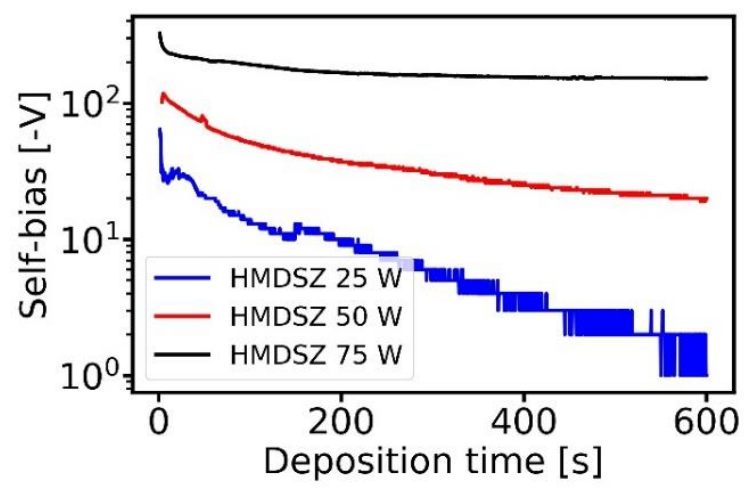

Figure 2 Evolution of self-bias during deposition for different power inputs

The dependence of the measured film thickness on the deposition time is plotted in Figure 3. From the thickness and deposition time it is possible to calculate the deposition rate. The time dependence of the deposition rate is also shown in Figure 3. From the graph it is clearly visible, that for thin films from HMDSZ precursor the deposition rate is less stable and after short deposition time the deposition rate dramatically decreases. This could be affected by physisorbed dust previously showed by confocal microscopy [6]. From graphs in Figure 3 it is also clear, that during depositions with higher power input than $25 \mathrm{~W}$ films are growing faster, but there is a minor difference between higher power inputs ( $75 \mathrm{~W}$ and $50 \mathrm{~W}$ ) than between lower inputs ( 50 and $25 \mathrm{~W}$ ). This is probably caused by fragmentation of molecules. This means that there is an ideal value of power input for deposition in which is a combination of homogeneous and heterogeneous reactions.
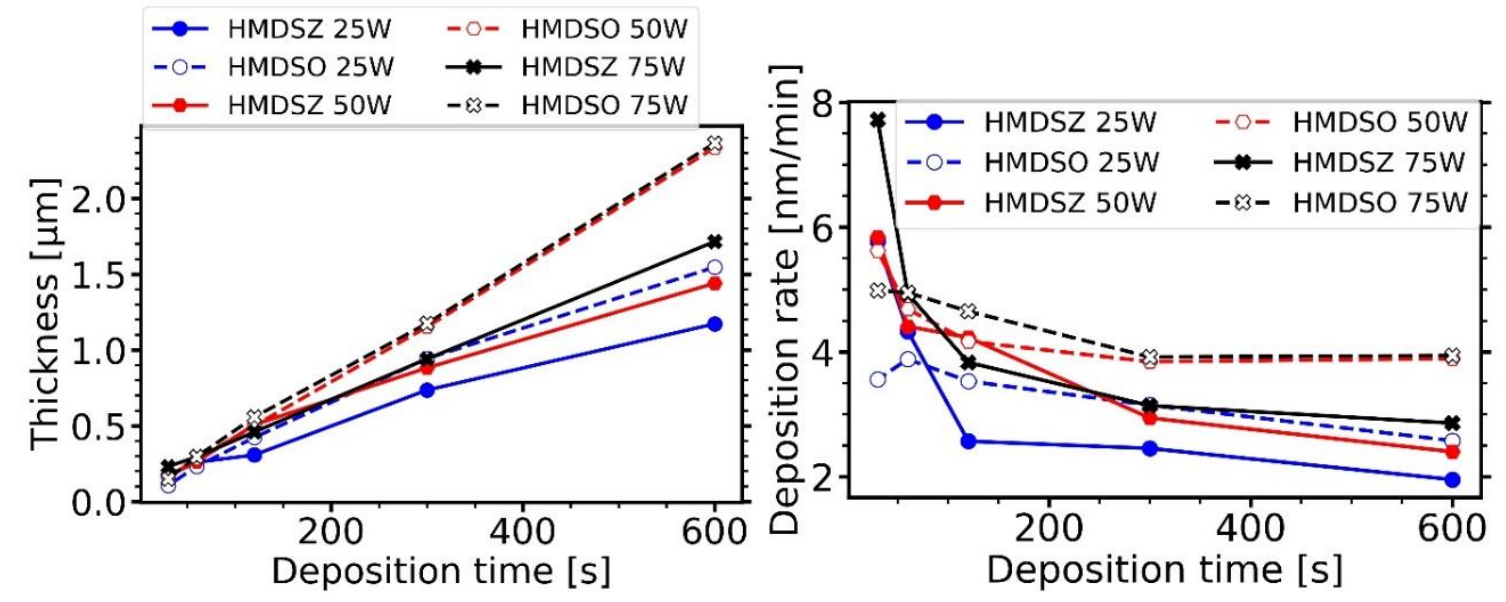

Figure 3 Left: Influence of deposition time on increasing a thin film thickness. Right: Graph showing decreasing deposition rate with deposition time.

Fragmentation of molecules causes the qualitative origin of dust in plasma. Formation of dust in plasma can be observed with diagnostic devices such as ICCD camera, but there is nontrivial behavior of dust in plasma. 
That means that the prediction of properties of thin films deposited in dusty plasma is nearly impossible with plasma diagnostic devices. Due to this fact, we are using AFM for the determination of dust quality and quantity on sample surfaces. Figure 4 shows surfaces of thin films deposited with different power inputs with deposition time $300 \mathrm{~s}$. From scans it is clearly visible, that HMDSZ makes bigger particles of dust in plasma. This verity corresponds with previously showed physisorbed macroscopic dust on samples [6]. This causes, that HMDSO thin films have better homogeneity. Moreover HMDSO thin films have surface roughness (RMS) in order of tenths of nanometers, whereas HMDSZ thin films have surface roughness between 5 to $50 \mathrm{~nm}$.

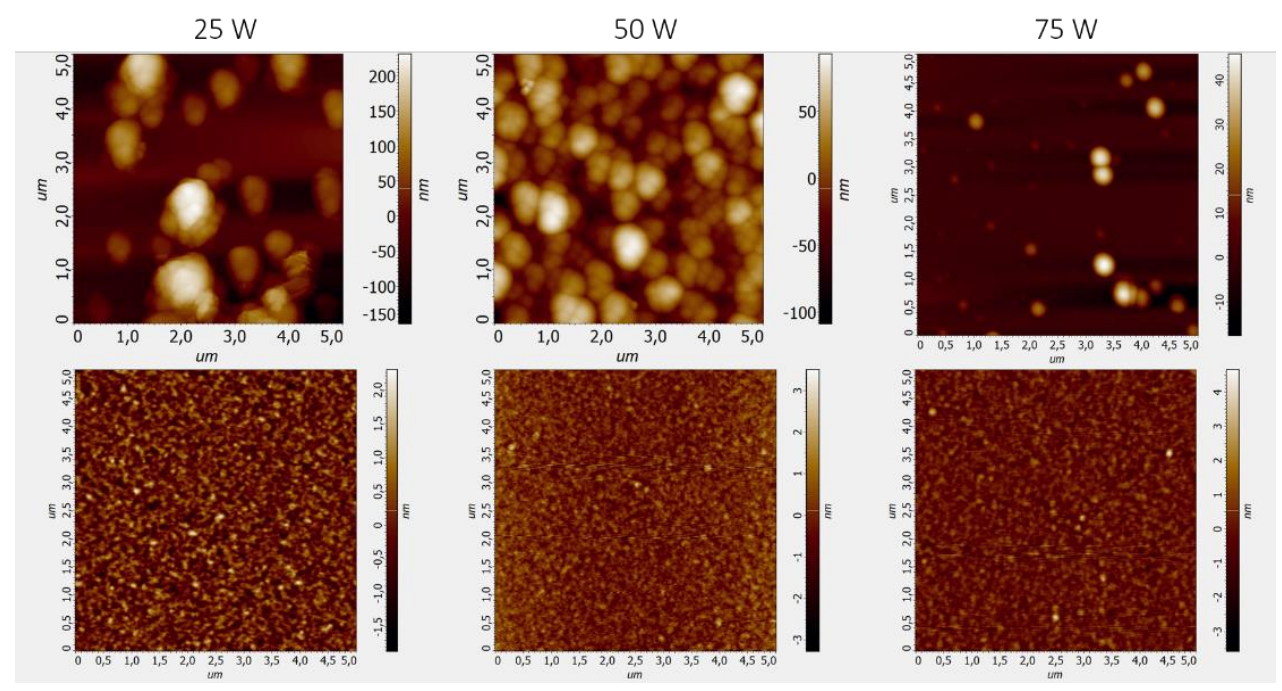

Figure 4 AFM scans of deposited films. First/second row shows films deposited from HMDSZ/HMDSO

Chemical composition was measured by FTIR and peaks were determined on the basis of these publications [11,12]. Thin films with deposition time of $60 \mathrm{~s}$ were chosen for this study. The results of the measurements are shown on Figure 5. From graphs it is visible that with increasing input power the larger fragmentation of $\mathrm{CH}_{\mathrm{x}}$ containing bonds occurs. For HMDSZ is this verity more noticeable because HMDSZ contains nitrogen in its chain $[1,2]$.
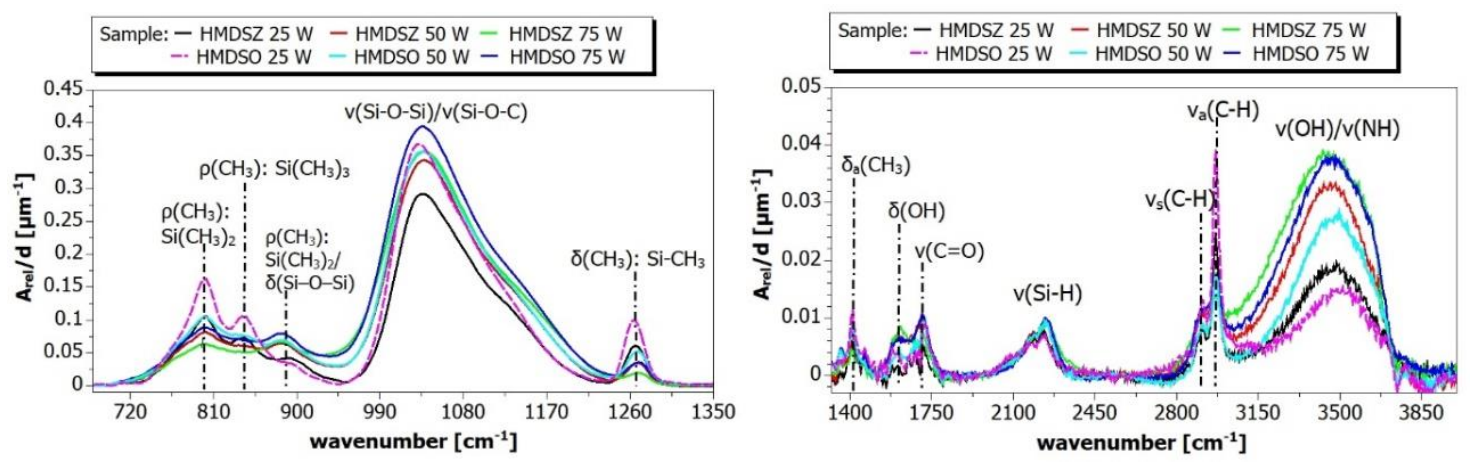

Figure 5 Measured FTIR spectra on samples with deposition time $60 \mathrm{~s}$

WCA was measured on glass substrates. Glass reference's WCA was $(62 \pm 2)^{\circ}$. Measured WCAs for deposited films are showed in the graph in Figure 6. From the graph is clearly visible, that all deposited films are more hydrophobic than the used substrate. The WCA is nearly stable and slightly decreases with increasing power input, whereas the highest value of WCA is probably caused by insufficient removal of macroscopic dust from the sample's surface. The hydrophobicity of deposited films is caused by $\mathrm{CH}_{x}$ groups [13]. 


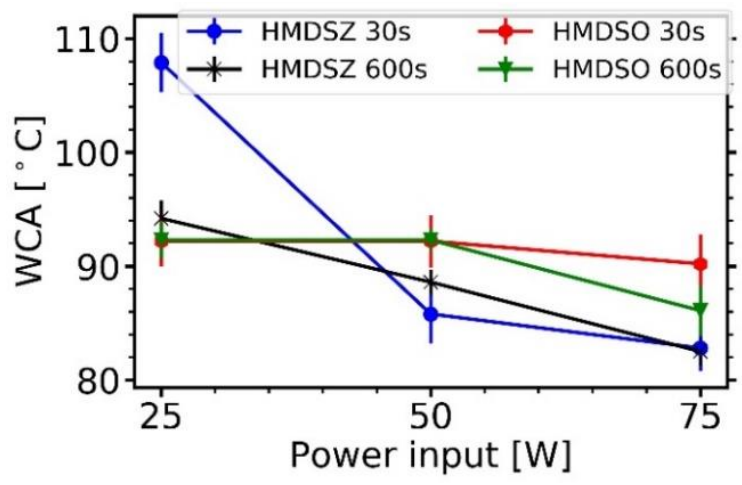

Figure 6 WCA for selected thin films

Indentation hardness (HIT) and reduced elastic modulus $\left(E_{r}\right)$ was measured by nanoindentation technique with

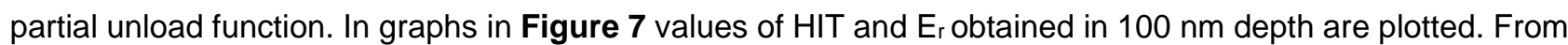
graphs is visible, that with HIT and $E_{r}$ are increasing with increasing power input.
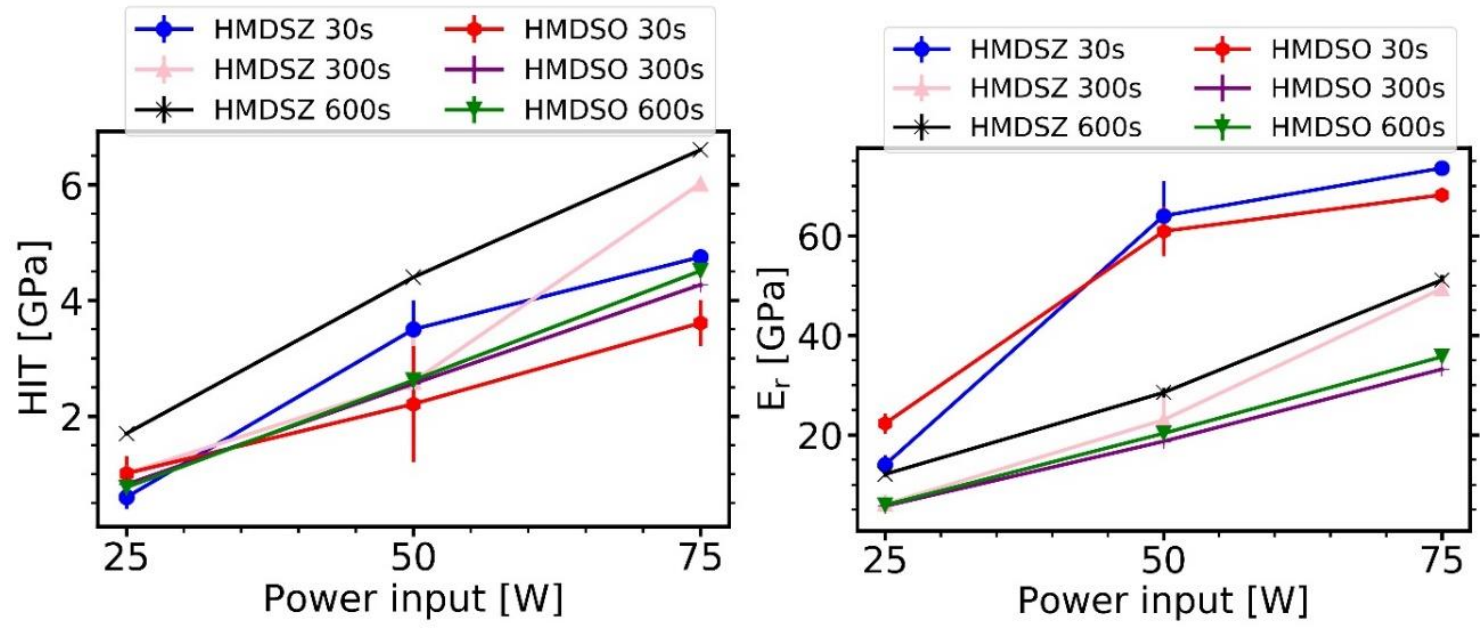

Figure 7 Values of HIT and $E_{r}$ in approximately $100 \mathrm{~nm}$ indentor depth

On the graph in Figure 7 there are shown results obtained for three deposition times, but values of HIT and $E_{r}$ are meaningful only for depositions with higher deposition time. This verity is shown in Figure 8, where the influence of silicon substrate for thin film from HMDSO precursor with deposition time $30 \mathrm{~s}$ is visible. Also from Figure $\mathbf{8}$ is nicely visible that all deposited thin films are viscoelastic.

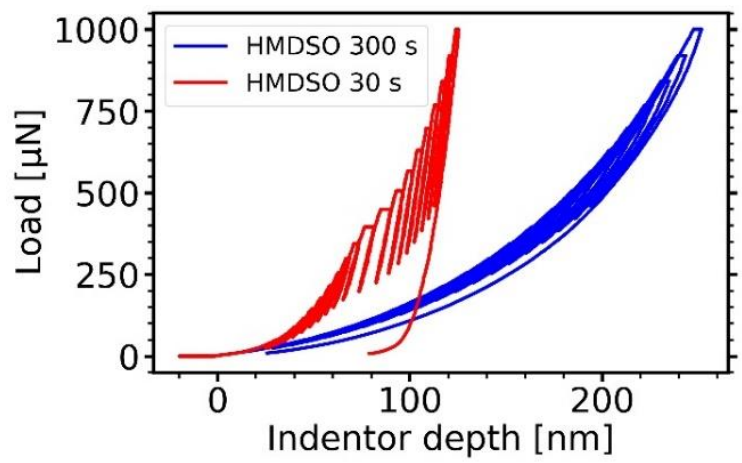

Figure 8 Quasistatic measurement of two films with input power 25 W 


\section{CONCLUSION}

The paper summarizes results from depositions in the atmosphere containing oxygen and HMDSO or HMDSZ precursor. The main reason for this study was to compare these types of thin film because of the wide usage of these precursors in a wide range of different reactors .For both precursors, there is an evolution of self-bias during the deposition process which causes the evolution of deposition rate. Despite the fact that the mixture of HMDSZ with oxygen creates bigger particles of dust, the deposition rate for HMDSO precursor is higher. Also due to bigger dust particles, the homogeneity of the surface is lower for thin films deposited from HMDSZ precursor. All deposited thin films have WCA around $90^{\circ}$ and all deposited thin films were viscoelastic.

\section{ACKNOWLEDGEMENTS}

The present work was supported by the Czech Science Foundation under project GACR 19-15240S, by the Ministry of Education, Youth and Sports of the Czech Republic under project NPU (LO1411).

\section{REFERENCES}

[1] PAVLENKO, S. Organosilicon chemistry. Berlin 1896.

[2] Hexamethyldisilazane. Merck [online]. Available from: https://www.sigmaaldrich.com/catalog/product/sigma/h4875?lang=en\&region=CZ

[3] Hexamethydisiloxane. Merck [online]. Available from: https://www.sigmaaldrich.com/catalog/product/aldrich/326739?lang=en\&region=CZ

[4] FRIDMAN, A. A. Plasma chemistry. Cambridge: Cambridge University Press, 2012. ISBN 978-1107684935.

[5] LIEBERMAN, M.A., LICHTENBERG, A. J. Principles of plasma discharges and materials processing. $2 \mathrm{nd}$ ed. Hoboken, N.J.: Wiley-Interscience, 2005. ISBN 0471720011.

[6] PŘIBYL, R., KELAROVÁ, Š., HOMOLA, V., BURČíKOVÁ, V. Development of Plasma Enhanced Chemical Vapor Deposition Reactor for Preparation of Oxygen Containing Organosilazane Polymer Thin Films [online]. In: International Conference on Nanomaterials NANOCON 2019. Brno: Tanger, 2020, pp. 637-641. Available from: https://doi.org/10.37904/nanocon.2019.8749

[7] HOMOLA, V., PŘIBYL, R., KELAROVÁ, Š., et al. Study of Nanostructured Plasma-Polymer Thin Films Growthunder Dusty Plasma Conditions [online]. In: International Conference on Nanomaterials NANOCON 2019. Brno: Tanger, 2020, pp. 642-647. Available from: https://doi.org/10.37904/nanocon.2019.8699.

[8] BOUCHOULE, A. (ed). Dusty Plasmas: Physics, Chemistry and Technical Impacts in Plasma Processing. New York: Wiley, 1999. pp. 77-180.

[9] SHUKLA, S., PADMA, K., MAMUN, A. A. Introduction to Dusty Plasma Physics. Bristol: Institute of Physics Pub., 2002

[10] BOUCHOULE, A., BOUFENDI, L. Particulate formation and dusty plasma behaviour in argon-silane RF discharge. Plasma Sources Science and Technology [online]. 1993, vol. 2, no. 3, pp. 204-213. DOI: 10.1088/0963-0252/2/3/011. ISSN 0963-0252. Available from: http://stacks.iop.org/09630252/2/i=3/a=011?key=crossref.8c4b30177541661a90505553151cb5b41

[11] GEGENBACH, T. R., GRIESSER, H. J. Post-deposition ageing reaction figger markedly between plasma polymers deposited from siloxane and silazane monomers. Polymer. 1999, vol. 40, p. 50795094.

[12] CASSERLY, T. B., GLEASON K. K. Chemical Vapor Deposition of Organosilicon Thin films from Methylmethoxysilanes. Plas. Proc. Polym. 2005, vol. 2, pp. 679-687, DOI: 10.1002/ppap.200500055.

[13] PARK, S. Y., KIM., N., KIM, U. Y., HONG, S., SASABE, H. Plazma polymerization of hexamethyldisiloxane. Polymer Journal. 1990, vol. 3, pp. 242-249.

[14] BONNAR, M. P., BURNSIDE, B. M., CHRISTIE, J., SCEAL, E. J., TROUPE, C. E., WILSON, J. I. B. Hydrophobic Coatings from Plasma Polymerized Vinyltrimethylsilane. Chemical Vapor Deposition. 1999, vol. 5, no. 3, pp. 117 125. Available from: https://doi.org/10.1002/(SICI)1521-3862(199906)5:3<117::AID-CVDE117>3.0.CO;2-4. 